\title{
Impact of Increasing Pumping Discharge on Groundwater Level in the Nile Delta Aquifer, Egypt
}

\author{
Asaad M. Armanuos ${ }^{1, *}$, Kamal Ahmed ${ }^{2,3}$, Mohammed Sanusi Shiru ${ }^{4,5}$, Mehdi Jamei ${ }^{6}$ \\ ${ }^{1}$ Irrigation and Hydraulics Engineering Department, Civil Engineering Department, Faculty of Engineering, Tanta \\ University, Egypt; \\ ${ }^{2}$ School of Civil Engineering, Faculty of Engineering, Universiti Teknologi Malaysia (UTM), 81310 Johor Bahru, \\ Malaysiakamal_brc@hotmail.com \\ ${ }^{3}$ Faculty of Water Resource Management, Lasbela University of Agriculture Water and Marine Sciences (LUAWMS), \\ 90150 Uthal, Balochistan, Pakistan \\ ${ }^{4}$ Department of Environmental Sciences, Faculty of Science, Federal University Dutse, P.M.B, 7156, Dutse, Nigeria; \\ msshiru@seoultech.ac.kr \\ ${ }^{5}$ Department of Civil Engineering, Seoul National University of Science and Technology, 01811, Seoul, Republic of \\ Korea \\ ${ }^{6}$ Faculty of Engineering, Shohadaye Hoveizeh University of Technology, Dasht-e Azadegan, Susangerd, Iran; \\ mehdi.jamei59@gmail.com \\ * Correspondence: asaad.matter@f-eng.tanta.edu.eg
}

Manuscript received: 11-06-2021, revised: 16-08-2021, accepted: 20-08-2021.

\begin{abstract}
The main goal of this research is to develop a 3D groundwater (GW) model using MODFLOW software to assess the potential effect of increasing pumping discharges on GW level in the Nile Delta Aquifer (NDA). In this study, the current state of the irrigation canals and GW recharge are considered in the GW model. The simulated GW level was compared with the observed GW level for model validation. Three vertical cross sections in western central and eastern areas of the ND are selected to check the impacts of GW pumping on variations of GW level. Ten scenarios of increasing the abstraction rates in all areas of the ND are tested. The results confirmed that increasing the pumping discharges has a substantial effect on decreasing the GW level in central and southern areas of the NDA. In addition, the tenth scenario is considered the last case where the drawdown of GW level reached $1.32,1.59$, and $2.41 \mathrm{~m}$ in the southern boundaries. The findings of the study should be considered when studying the management of GW resources and the impacts of climate change on the ND.
\end{abstract}

Keywords: Nile Delta Aquifer; GW pumping scenarios; GW level; pumping wells.

\section{Introduction}

Many countries around the world are reliant on groundwater $(\mathrm{GW})$ for various water needs. Egypt is among the nations that depend mainly on GW to meet water demands. The quality of GW sources has continuously been deteriorating and this has threatened its uses [1]. The Nile River is a major contributor to the surface water of the Nile delta (ND), contributing nearly $35.5 \mathrm{~km}^{3} /$ year. It also recharges the NDA by canals leakages and excess irrigation water to the aquifer, thereby serving as a major source of recharge [2]-[4]. The extent of GW inflow from the excess irrigation water of the Nile River varies from $0.25-1.1 \mathrm{~mm}$ per day [5] while the contribution from agricultural recharge stands at $0.8-1.1 \mathrm{~mm}$ per day for old area lands and $1.9-2.1 \mathrm{~mm}$ per day for the reclaimed lands [6]. Various authorities have explored the rates of GW recharge in the ND aquifer using various water balance methods; the outcomes showed that the rate varies from $5-10 \%$ of the input water volume of around $2-4 \mathrm{~km}^{3} /$ year [7]. The study by Armanuos et al. [8] focused on the use of the WetSpass hydrological model to determine the rates of GW recharge from the rainfall in the ND aquifer over a period of 6 years. The validation of the ND model parameters has normally been based on crop classification. The average rate of GW recharge in the ND aquifer between 2000 and 2010 varied from $0.0-134 \mathrm{~mm}$ in each winter season. The possible effect of the Grand Ethiopian Renaissance Dam (GERD) on the ND aquifer has been investigated by Armanuos et al. [9] using the MODFLOW code; the study also studied the abstraction scenarios on the level of GW. The study implemented a three-dimensional GW model while considering the whole irrigation canals in the ND region. Model testing was done in 3 different scenarios: (i) decreasing depths of the water canal, (ii) increasing rate of abstraction from the ND aquifer, and (iii) combination of the two scenarios. The results observed a higher impact on GW level when increasing the abstraction from the aquifer compared to the 
reduction of the depths of the water canals due to the decline in the volume of water entering and leaving the GW in the ND aquifer caused by the presence of the upper clay layer. The last scenario was the most pessimistic as evidenced by the increase in the average drawdown value in the western $(1.26 \mathrm{~m})$, middle $(1.7 \mathrm{~m}) \&$ eastern $(1.35 \mathrm{~m})$ regions of the ND. Kashef [3] noted that the water supply to the industrial sector from the ND aquifer system is about $1.6 \times 10^{9} \mathrm{~m}^{3} /$ year. Egypt's irrigation ministry observed that the total abstraction volume due to irrigation stands at $0.82 \mathrm{~km}^{3} / \mathrm{hr}$ while the overall water supply for irrigation to the industrial sector stands at 2.42 $\mathrm{km}^{3} / \mathrm{hr}$. The total yearly GW extraction in the ND system for domestic and irrigation purposes reached $2.123 \mathrm{x}$ $10^{9} \mathrm{~m}^{3} /$ year in 1993 [10] while the cumulative volume of abstraction in 1992 was around $1.92 \times 10^{9} \mathrm{~m}^{3} / \mathrm{year}$ as per the extraction well database. The highest number of extraction wells (3391) is in the El Gharbia governorate, while Sharkia \& Menoufia governorates have 1953 \& 1719 extraction wells, respectively [11]. RIGW also conducted an inventory of the ND abstraction well for the following years 1995, 1997, \& 2002. Hence, data sheets were uploaded for the computation of the quantity of abstraction in 2008. The overall abstraction rate from the ND was $3.03 \times 10^{9} \mathrm{~m}^{3}$ per year in 1992 , and $4.90 \times 10^{9} \mathrm{~m}^{3} /$ year in 2008 [12]. The study by Serag El Din [13] reported an upward GW flow of around $3 \times 10^{3} \mathrm{~m}^{3}$ year towards the upper clay layer due to saltwater intrusion; the study also reported the rate of GW recharge in the ND to be almost three times the upward loss volume. An increase in the annual total extraction volume from the aquifer was also observed, rising from $1.6 \times 10^{9} \mathrm{~m}^{3}$ in 1981 to $2.6 \times 10^{9} \mathrm{~m}^{3}$ in 1991 ; there was also a marginal increase to $3.2 \times 10^{9} \mathrm{~m}^{3}$ in 1997 and $3.5 \times 10^{9} \mathrm{~m}^{3}$ in 2003. Increase in total extraction volume was also noted between 2003 and 2010 , reaching $4.5 \times 10^{9} \mathrm{~m}^{3} /$ year which is an increase of $0.2 \times 10^{9} \mathrm{~m}^{3} /$ year [14].

Being that the available GW in the NDA and its desert borders is recharged from the Nile River (coming from canal leakages and percolation from irrigation systems), it is not considered a GW source on itself [15]. The ND and its fringes have an overall pumping volume of around $4.6 \times 10^{9} \mathrm{~m}^{3}$; however, the desert aquifers and the coastal zones contribute only about $0.5 \times 10^{9} \mathrm{~m}^{3}$ of this volume. The overall $\mathrm{GW}$ withdrawal from the ND per year is predicted to reach $11.4 \times 10^{9} \mathrm{~m}^{3}$ in 2015 because of the perceived significance of $\mathrm{GW}$ in national the proper management of GW resources. This work is aimed at MODFLOW software-based assessment of the possible impacts of the increasing pumping scenarios on the levels of GW in the ND aquifer; this will aid in the creation of a 3D model of the ND aquifer.

\section{Study area description}

The ND is a 25,000-square-kilometer area in northern Egypt (MWRI 2013). The ND is bordered on the north by the Mediterranean Sea and on the south by the Nile River, in the east, the Suez and Ismailia canals, and in the west, the El Nobaria canal, (MWRI 2013). The Nile River is separated into nine major canals in the ND district. It has two primary branches: Rosetta and Damietta. The Rosetta branch is situated on the west side and is approximately 239 kilometers long, while the Damietta branch is situated throughout the east side and is approximately 245 kilometers long [3]. The NDA's GW system is a complicated one. The Quaternary aquifer of the ND is a semi-confined, with a clay layer covering it at the surface [16], [17].

The aquifer thickness starts at 200 meters in the south and rises to 1000 meters in the north [11]. The top layer of clay serves as an aquitard throughout the south and has a thickness of 5 to 25 meters, whereas in the north it has a thickness of more than 50 meters and serves as an aquiclude (Said 1962). In the winters of the year of 2000 and the year of 2010, GW recharge in the NDA varied from 0.0 to $134 \mathrm{~mm}$ in Cairo and Alexandria, consequentially [8]. Percolation to the ND Quaternary aquifer averages $0.8 \mathrm{~mm}$ per day1 [18]. The NDA's hydraulic conductivity rises in the south and west directions. The aquifer medium is known to have an effective porosity of 0.3 . RIGW recorded the storage coefficient and transmissivity values to be 2.510-3 and 5,000 m/day, accordingly [19]. In the NDA, the depth extended from the land surface to the GW level rises from north to south. It ranges between 1 and 2 meters in the northern part, rises to 3 to 4 meters in the middle part, and reaches its peak of 5 meters in the southern part [20].

\section{Methodology}

To derive the governing equations of GW flow, the water balance and Darcy's law were mathematically combined and used [21]. The creation of the 3D model of the NDA was done using a grid structure of 292 vertical columns \& 190 horizontal rows; the dimension of the cells was $1.0 \mathrm{~km}$ x $1.0 \mathrm{~km}$ while the depths along the Mediterranean Sea's shore ranged from 1,000 m in the north to $200 \mathrm{~m}$ near to Cairo city in the south (see Figure 1). There are 7 layers of the constructed model; Layer 1 represents the upper clay layer and Layers 2-7 represent the quaternary layer of the ND. The three various vertical cross sections namely $(1-1,2-2$, and 3-3) of the ND model are shown in Figures $2 \mathrm{a}-\mathrm{c}$.

The hydraulic gradient of GW flows beginning the south (Cairo city) towards the north (Mediterranean Sea) in the ND aquifer is $11.0 \mathrm{~cm} / \mathrm{km}$ in the south and $7.0 \mathrm{~cm} / \mathrm{km}$ in the north. The literature specified 
a constant head of 16.96 above msl for the southern boundary of the ND model [12], [22]. A zero value was also specified for the upper boundary condition along the Mediterranean Sea's shore in the north. The eastern boundary is left free in the area that hosts the Suez Canal. The Ismailia canal bounds with the model in the southeast; the water level in the south begins at 16.17 amsl and ends in the east 7.01 amsl.

The ND model is constrained in the southwest by the El Rayah El Behery and El Nubaria canals, with water levels ranging from $16.00 \mathrm{~m}$ amsl in the south boundary to $0.50 \mathrm{~m}$ amsl in the north boundary. Mariot, Idku, Burullus, and Manzala, the ND's four main lakes, were allocated to the NDA model as a constant head since they are mainly linked with the Mediterranean Sea.

The MODFLOW model describes the groundwater flow in anisotropic and nonhomogeneous and medium according to the following equation:

$$
\frac{d}{d x}\left(K_{x x} \frac{d h}{d x}\right)+\frac{d}{d y}\left(K_{y y} \frac{d h}{d y}\right)+\frac{d}{d z}\left(K_{z z} \frac{d h}{d z}\right)-W=S_{s} \frac{d h}{d t}
$$

where $K_{x x}, K_{y y}, K_{z z}$ are values of hydraulic conductivity in x, y and z directions $\left(L T^{l}\right)$; h is the piezometric head $(L) ; W$ is a volumetric flux per unit volume of aquifer representing sources and/or sinks of water $\left(T^{-l}\right) ; S_{S}$ is the specific storage $\left(L^{-1}\right)$ and $t$ is time $(T)$.

The MODFLOW river package was implemented to specify the input properties of the Damietta and Ros etta branches, as well as the Rayahs and the model's main canals. The main drains of the ND were modeled using MODFLOW's drain package. The model was built using the bank level and top canal width of irrigation canal systems estimated by Armanuos et al. [8]. Figure 1 depicts the canal distribution that will be used to build the model. Excess irrigation water recharge is determined by the soil media, irrigation schemes, and drainage system apportioned to the ND model according to Morsy's recorded values (2009) [12]. The annual abstraction rate per each governorate in the ND area has been assigned to the model in the year of 2008. Whereas, in 2008, the overall volume of abstraction from the ND's total area was about $2.78 \mathrm{Mm}^{3} /$ year [12]. The model was run several times during the calibration phase to reduce the difference between the observed hydraulic head by RIGW in the year of 2008 and the simulated head.

The ND GW model has been run for ten different pumping rates scenarios, by increasing the pumping discharges rates by $10,20,30,40,50,60,70,80,90$, and 100\%. The simulated GW level maps for the abstraction rate scenarios have been compared with the current case in the year 2008. The GW level in three cross sections located in western, central, and eastern parts has been introduced. The corresponding drawdown in GW level was calculated considering the GW level in the year 2008 is the base scenario.

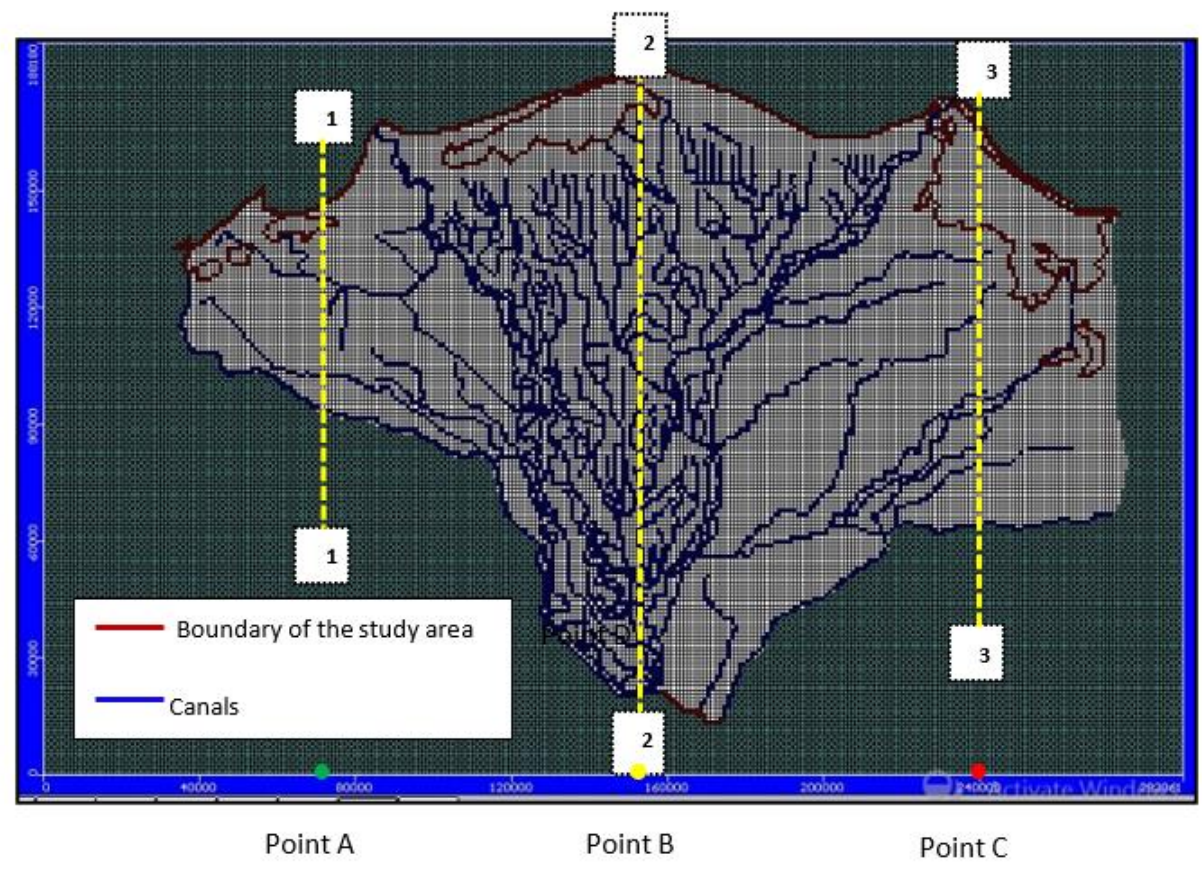

Figure 1. NDA model geometry and discretization. 


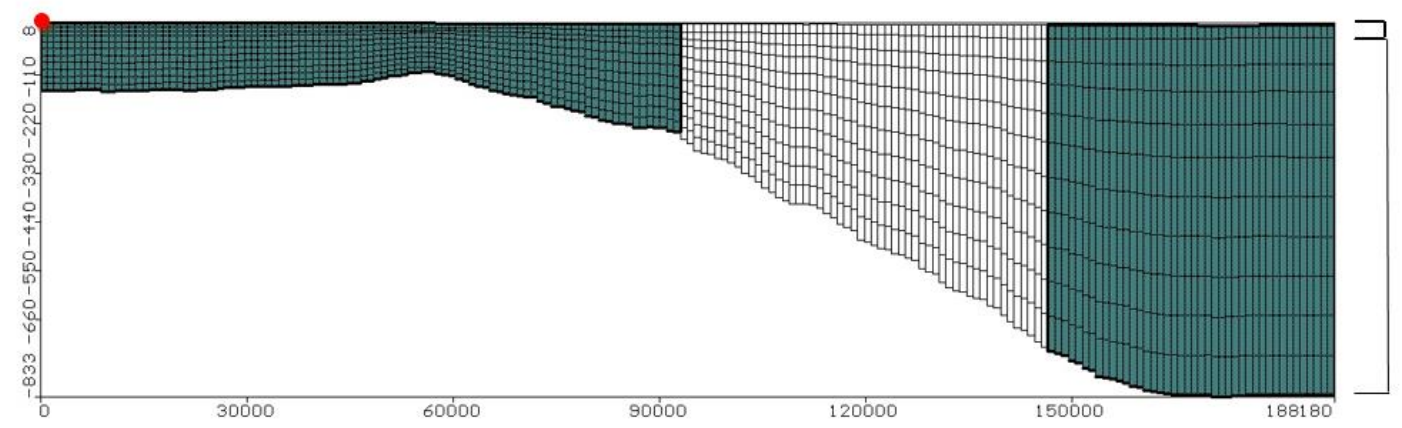

a. Cross section 1-1

Point B

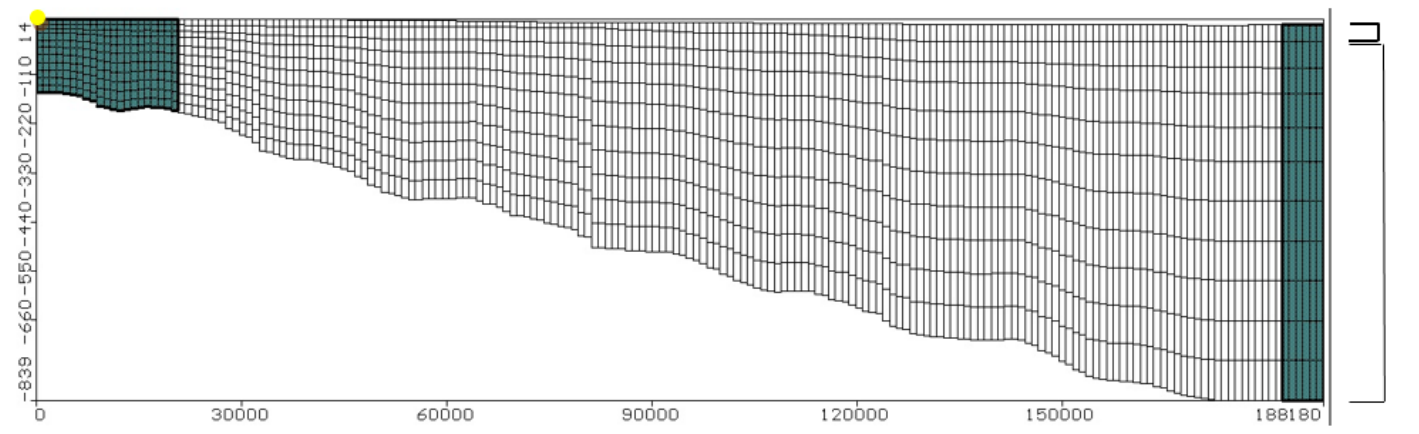

Layer 1

Layer 2

b. Cross section 2-2

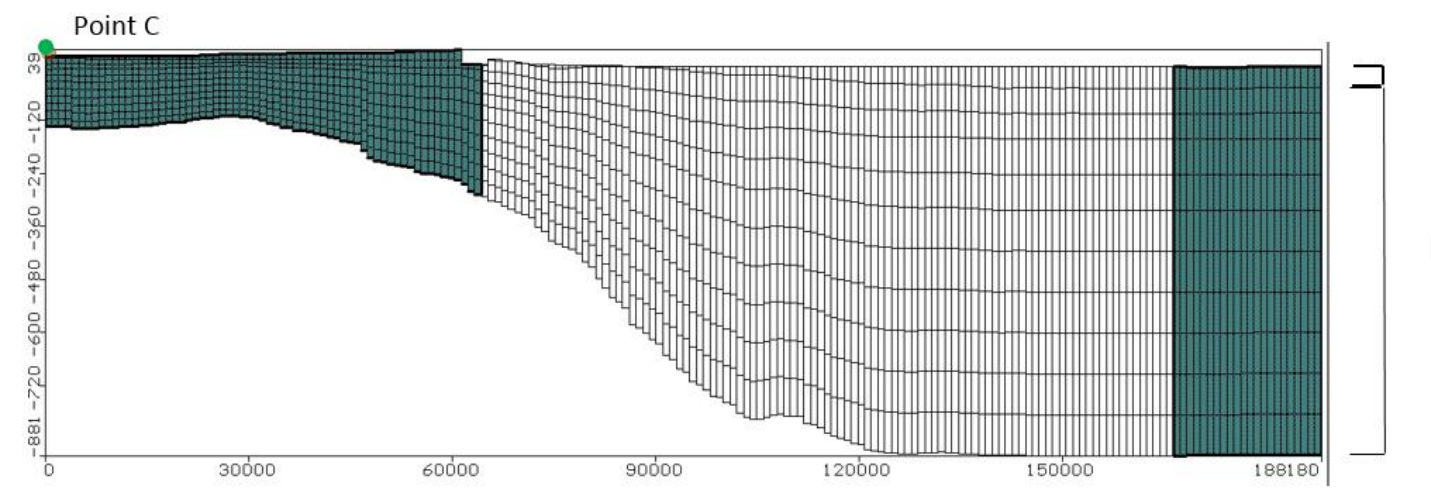

Layer 1

Layer 2

c. Cross section 3-3

Figure 2. Vertical Cross sections in the NDA Model: 1-1, 2-2 and 3-3.

\section{Results and discussion}

For various values of horizontal $\mathrm{K}_{\mathrm{x}}$ of the top clay layer, the RMSE between the observed and predicted GW head remained constant with no change. The proportion of vertical to horizontal $\mathrm{K}_{\mathrm{x}}$ is equivalent to $10 \%$. The calibrated range of the first layer's vertical $\mathrm{K}_{\mathrm{y}}$ range from 0.01 to $0.025 \mathrm{~m} /$ day. The calibrated horizontal $\mathrm{K}_{\mathrm{x}}$ of the quaternary layer and it varies from 50 to $240 \mathrm{~m} /$ day. The measured and simulated GW levels are presented in Figures $3 \mathrm{a}$ and $\mathrm{b}$. Figure $4 \mathrm{a}$ shows the comparison of measured and modeled GW levels for 60 records collected by RIGW in 2008 from various observation wells for model calibration. The correlation factor $\mathrm{R}^{2}$ and the root mean square error (RMSE) in between the measured and simulated GW level, reached 0.9763 and $0.60 \mathrm{~m}$, accordingly. The comparison of measured and simulated GW levels for the other 60 well records selected for model validation is shown in Figure $4 \mathrm{~b}$. The RMSE is $0.60 \mathrm{~m}$, and the correlation coefficient $\mathrm{R}^{2}$ between the simulated and measured head is 0.9771 . Figures 5a to 5e present the GW level distribution in the ND for increasing the abstraction rate by $10,20,30,40$, and $50 \%$ respectively. While Figures 6 a to 6e compare the GW level for increasing the pumping discharges by $60,70,80,90$, and $100 \%$ consequentially. Increasing the pumping discharges cause the GW level to decrease in all areas of the ND region. The GW level for the base 
case, in the year 2008, ranges from zero to $16.99 \mathrm{~m}$ amsl near the south boundary. Increasing the pumping discharges by 10, 20, 30, 40, and 50\% leads the GW level to move southward. The contour lines 1.0, 2.0, and 3.0 $\mathrm{m}$ for GW level moved from the northern area to central area of the ND. As presented in figure 6, the contour lines 1.0, 2.0, and $3.0 \mathrm{~m}$ moves more to southward as increasing the pumping discharges by percentages 60, 70, 80,90 , and $100 \%$. The three contour lines reach the south end of the model in western and eastern areas. In addition, the other contour lines 4.0 to $16.99 \mathrm{~m}$ moves, the spaces between the contour lines decreases more and becomes close. The last scenario is considered the worst case where the pumping discharges is doubles, the drawdown increases more in western, central, and eastern areas.

Figures 7a to 7c shows the GW level in three vertical cross sections for ten different pumping scenarios in western, central, and eastern parts respectively. The length of cross sections from the shoreline to the south boundary equals 47,163 , and $102 \mathrm{~m}$ for cross sections in western, central and eastern parts respectively. According to cross section 1, the GW level in eastern parts ranges from zero at the shoreline to $2.4 \mathrm{~m}$ amsl in the south boundary. Increasing the bumping discharges to 20, 40, 60, 80, and 100\% leads the GW level to decline and reach $2.29,1.98,1.73,1.46$, and $1.196 \mathrm{~m}$ respectively. In the central parts, as shown in cross section 2 , increasing the bumping discharges to $20,40,60,80$, and $100 \%$ leads the GW level to decline and reach 14.76 , $14.45,14.11,13.75$, and $13.39 \mathrm{~m}$ respectively compared with $14.98 \mathrm{~m}$ for the base case. In the eastern parts, as shown in figure $7 \mathrm{c}$, for cross section no.3, increasing the bumping discharges to $20,40,60,80$, and $100 \%$ leads the GW level in the south boundary to decline and reach $2.46,1.96,1.48,0.95$, and $0.48 \mathrm{~m}$ respectively compared with 2.89 for the base case. Figures $8 \mathrm{a}$ to $8 \mathrm{c}$ shows the drawdown in $\mathrm{GW}$ level in three vertical cross sections, in the NDA, for ten different pumping scenarios in western, central, and eastern parts respectively. According to cross section 1, increasing the bumping discharges to 20, 40, 60, 80, and 100\% leads the drawdown in GW level to increase and reach $0.138,0.439,0.697,0.968,1.232 \mathrm{~m}$ respectively. In the central parts, as shown in cross section 2, increasing the bumping discharges to 20, 40, 60, 80, and 100\% leads the GW level to decline more and the drawdown reach $0.22,0.53,0.87,1.23$, and $1.59 \mathrm{~m}$ respectively. In the eastern parts, as shown in figure $6 \mathrm{c}$, for cross section no.3, increasing the bumping discharges to $20,40,60,80$, and $100 \%$ leads the drawdown to increase in the south boundary and reach $0.43,0.93,1.41,1.94$, and $2.41 \mathrm{~m}$ respectively. The last scenario is considered the worst scenario as the drawdown in GW level reached 1.23, 1.59 , and $2.41 \mathrm{~m}$ in western, central, and eastern areas of the ND region, consequentially.

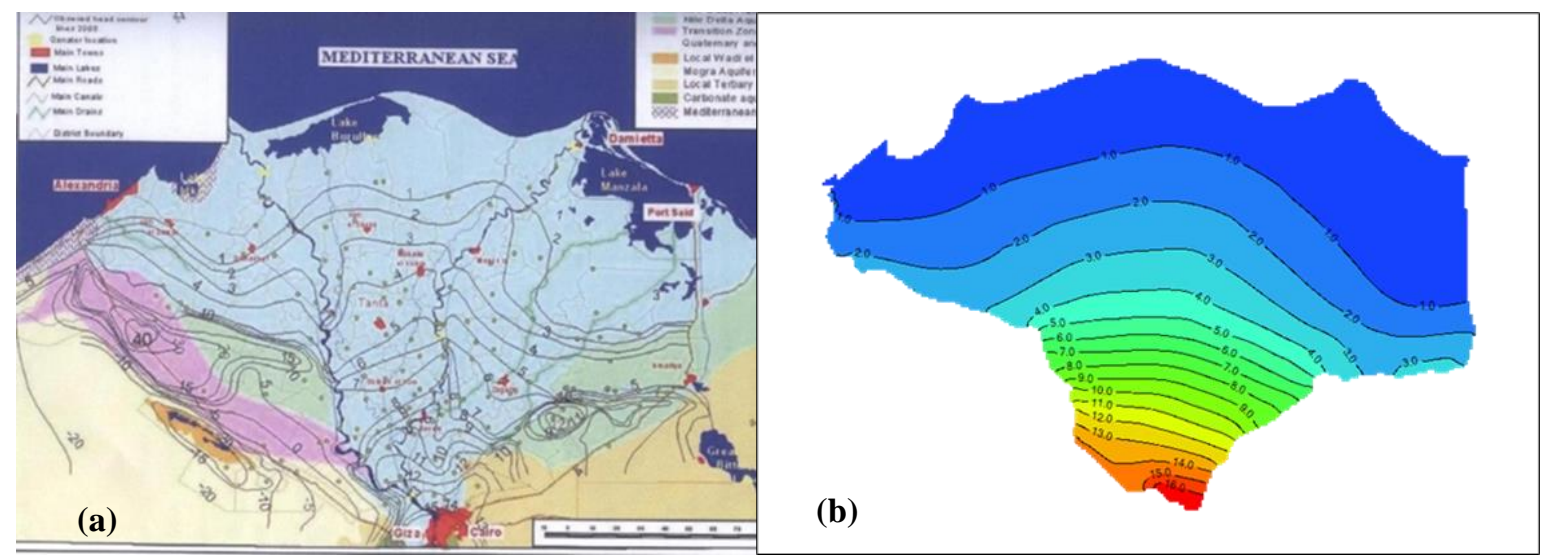

Figure 3. GW Head in the NDA 2008, (a) Observed GW level and (b) Simulated GW level [12]. 
(a)

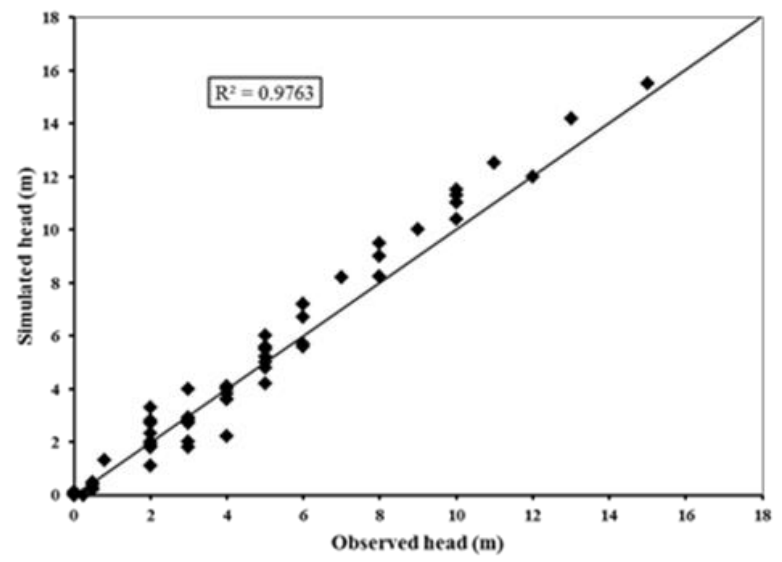

(b)

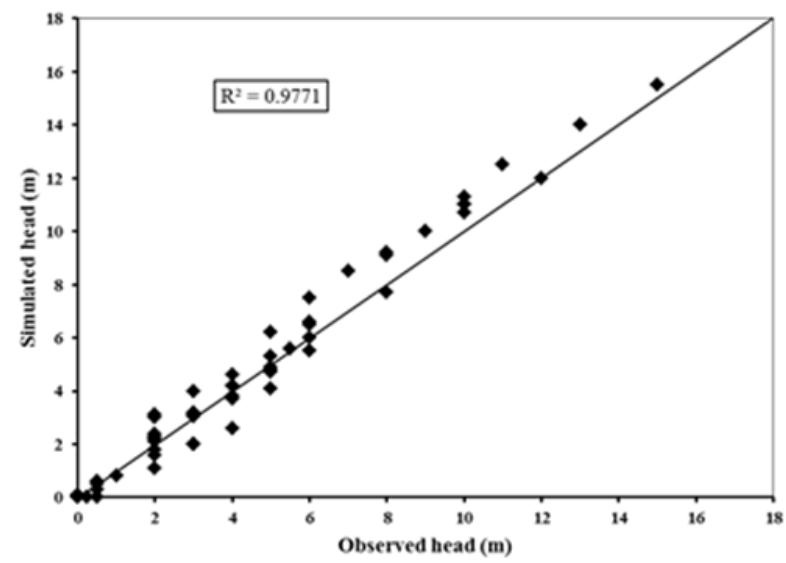

Figure 4. Comparison between the observed and simulated GW levels for a. calibration and b: validation process.

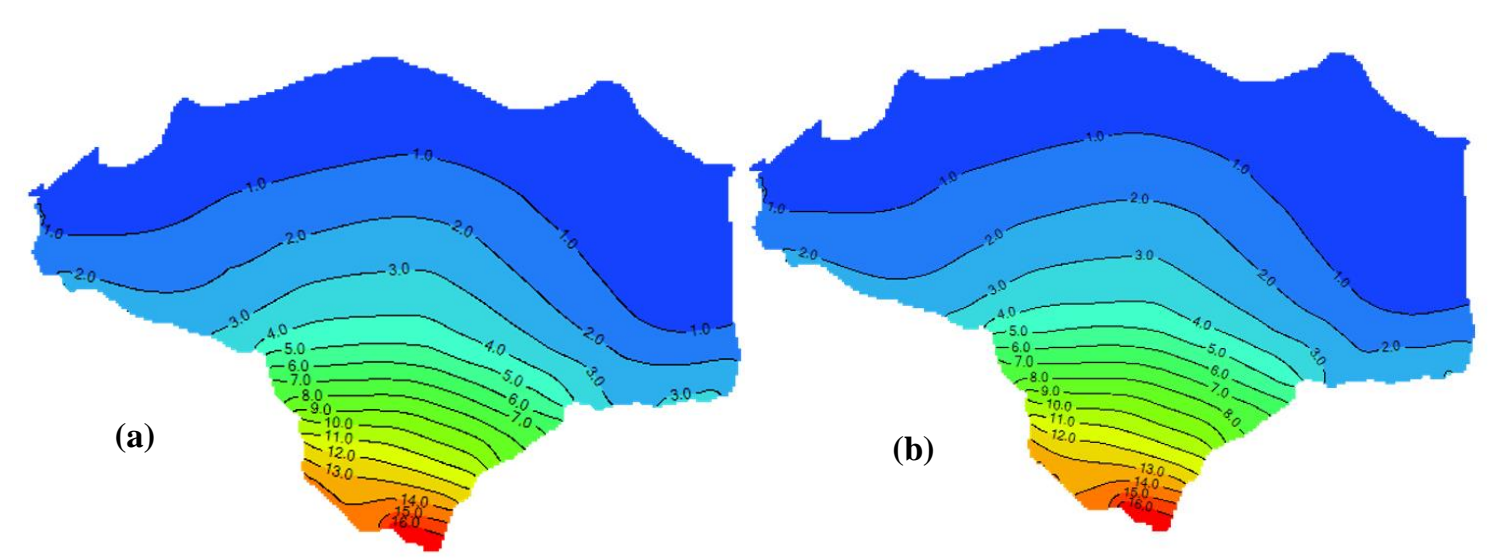



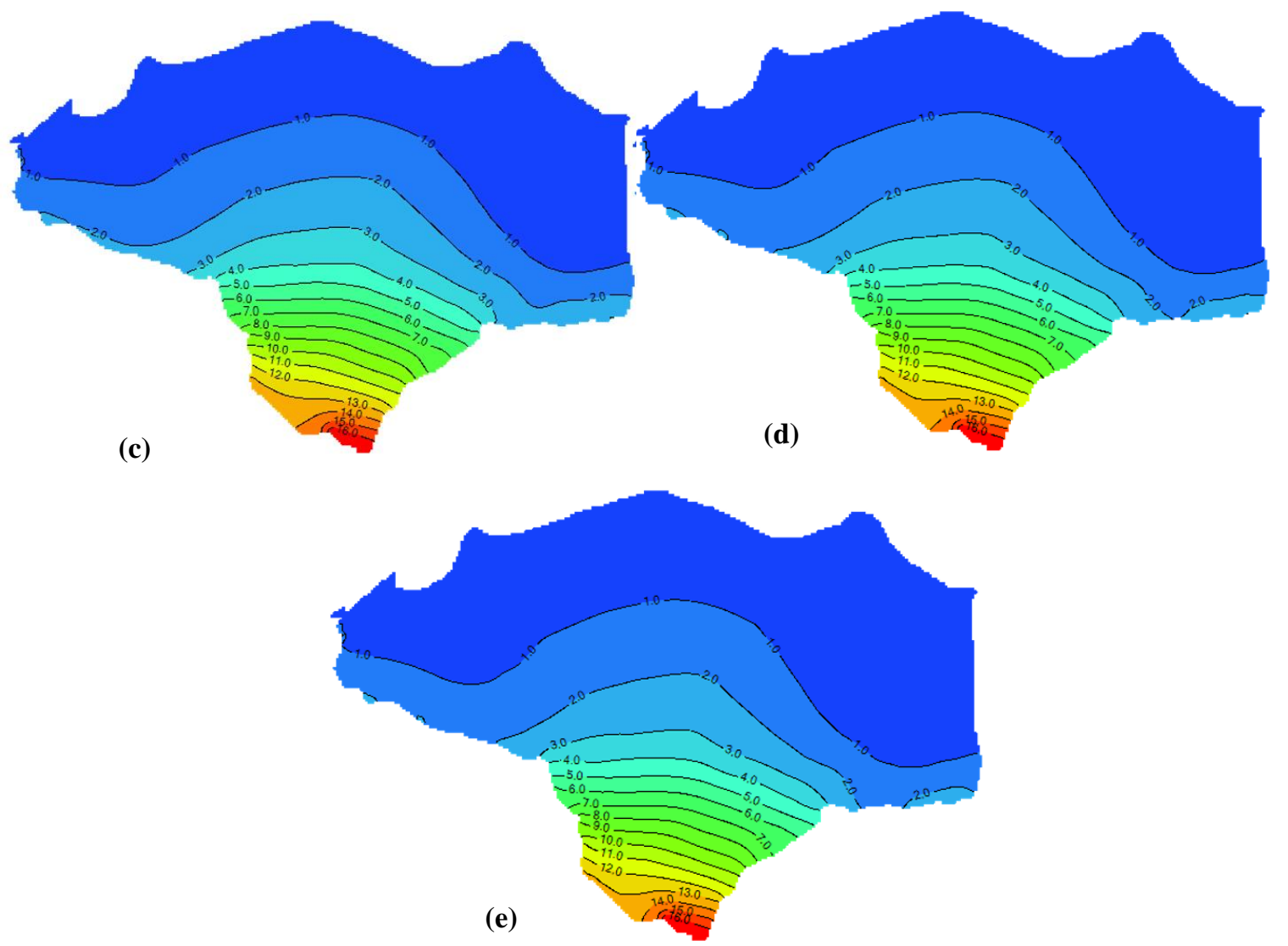

Figure 5. GW level distributions in the NDA for increasing pumping discharges by for a. 10\%, and b. 20\%, c. $30 \%$, d. $40 \%$, and e. 50 .
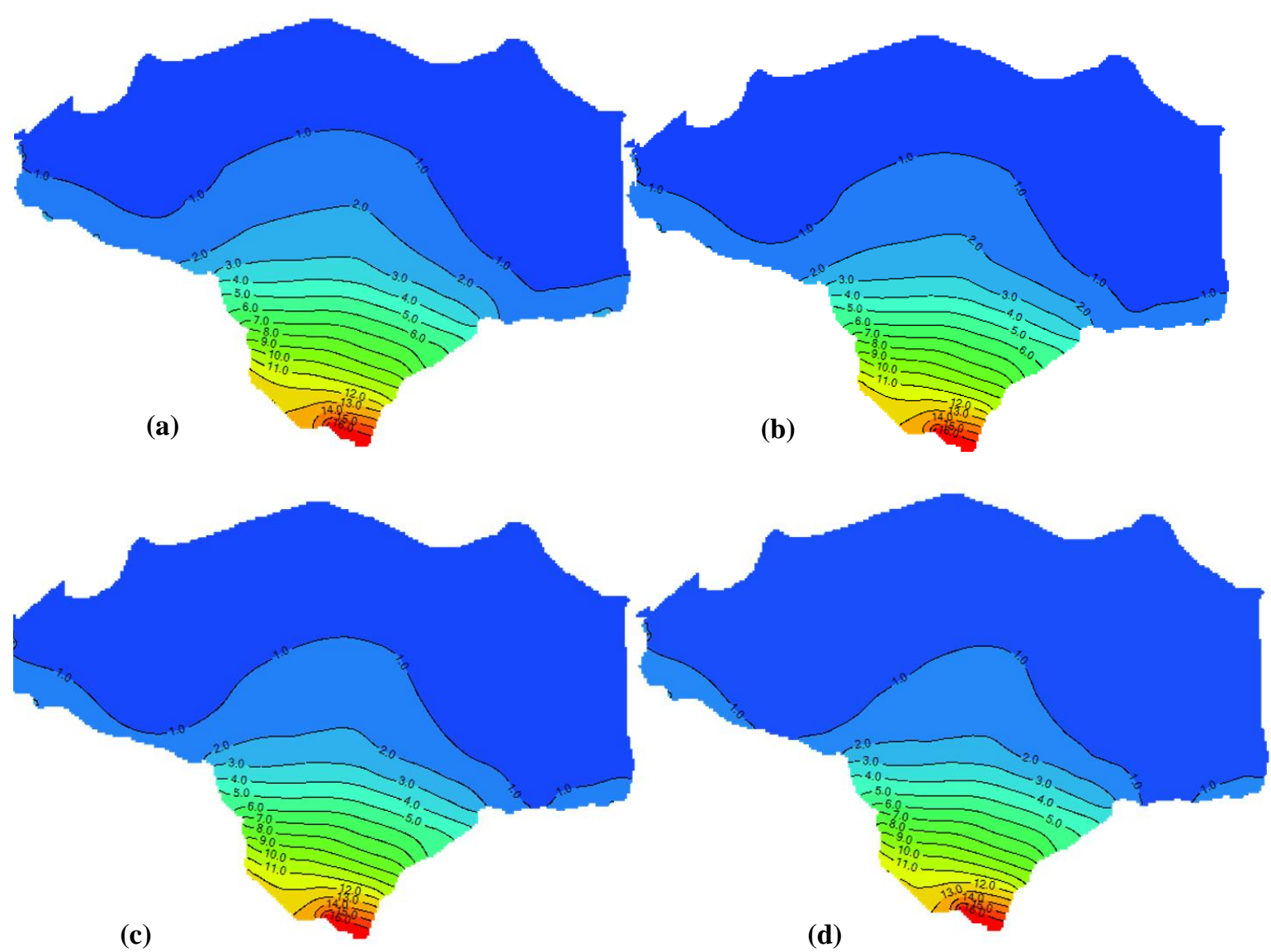

Page 7 of 11 


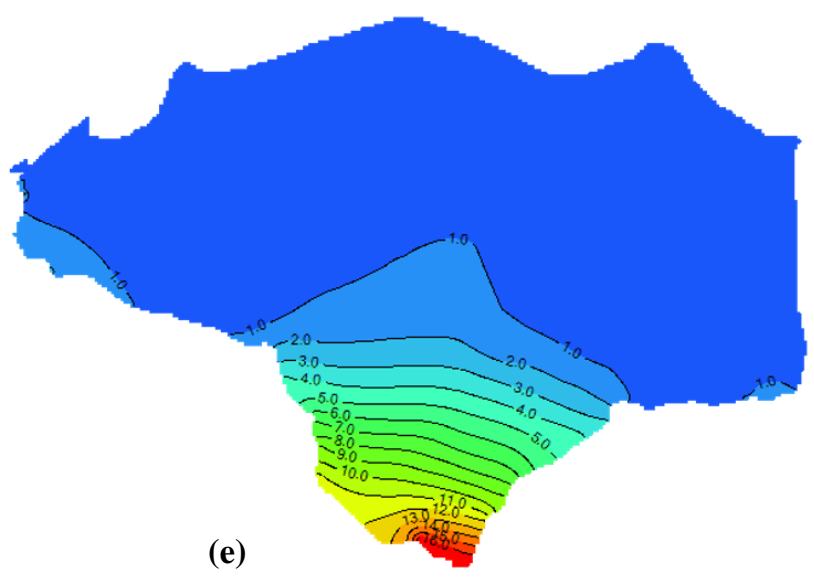

Figure 6. GW level distributions in the NDA for increasing pumping discharges by for a. $60 \%$, and b: $70 \%$, c. $80 \%$, d. $90 \%$, and e. $100 \%$.
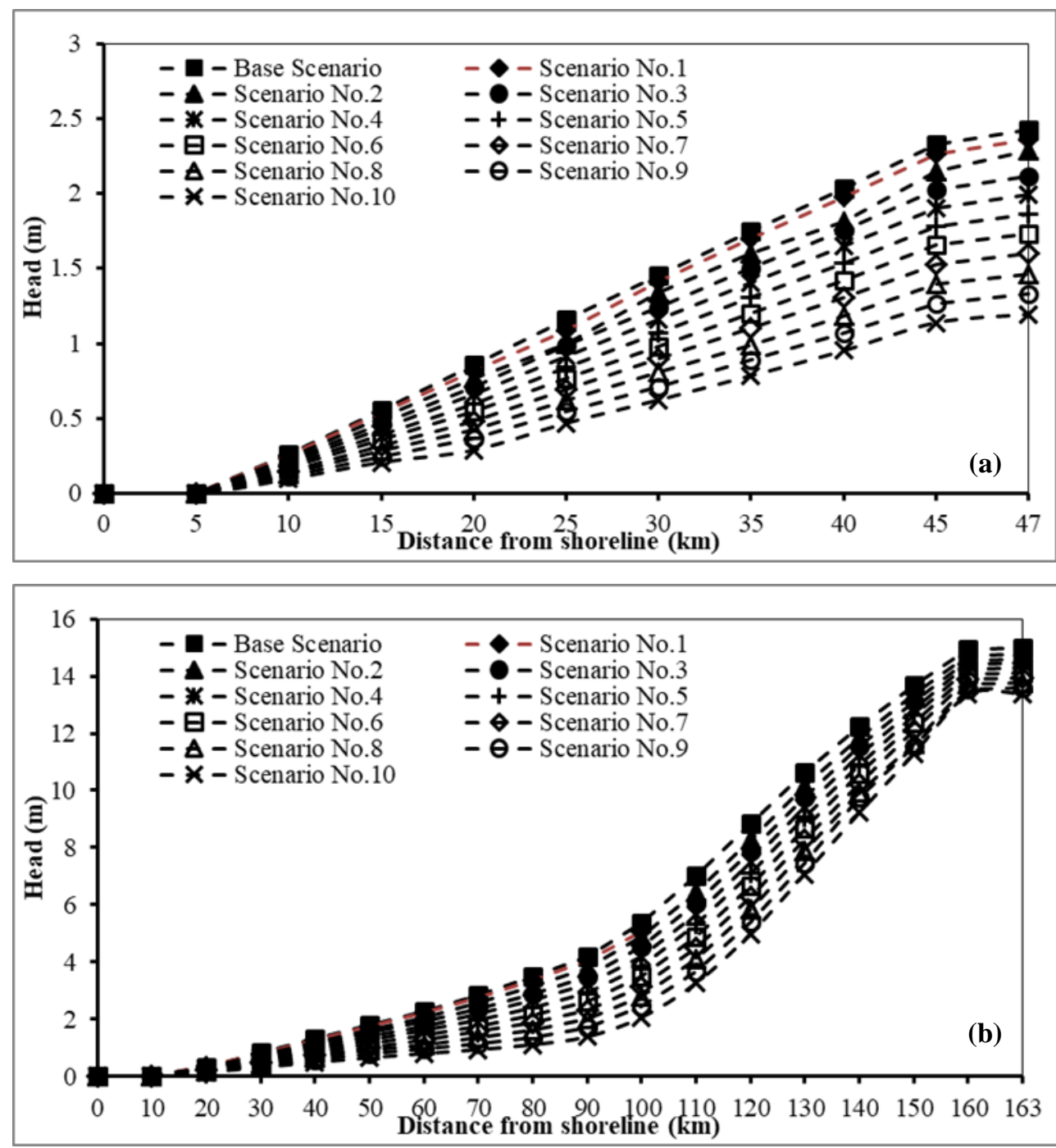


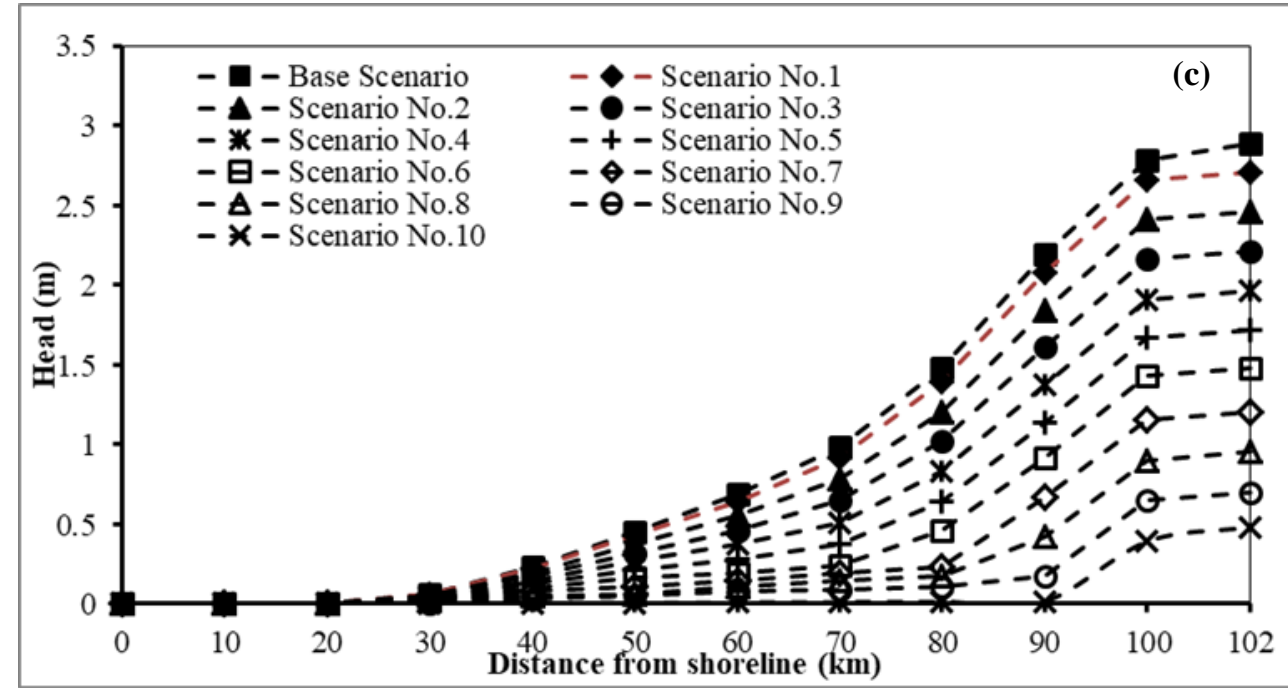

Figure 7. GW level in the NDA for different pumping scenarios for three vertical cross sections: a. 1-1 (western), and b: 2-2 (central), and c.3-3 (Eastern).
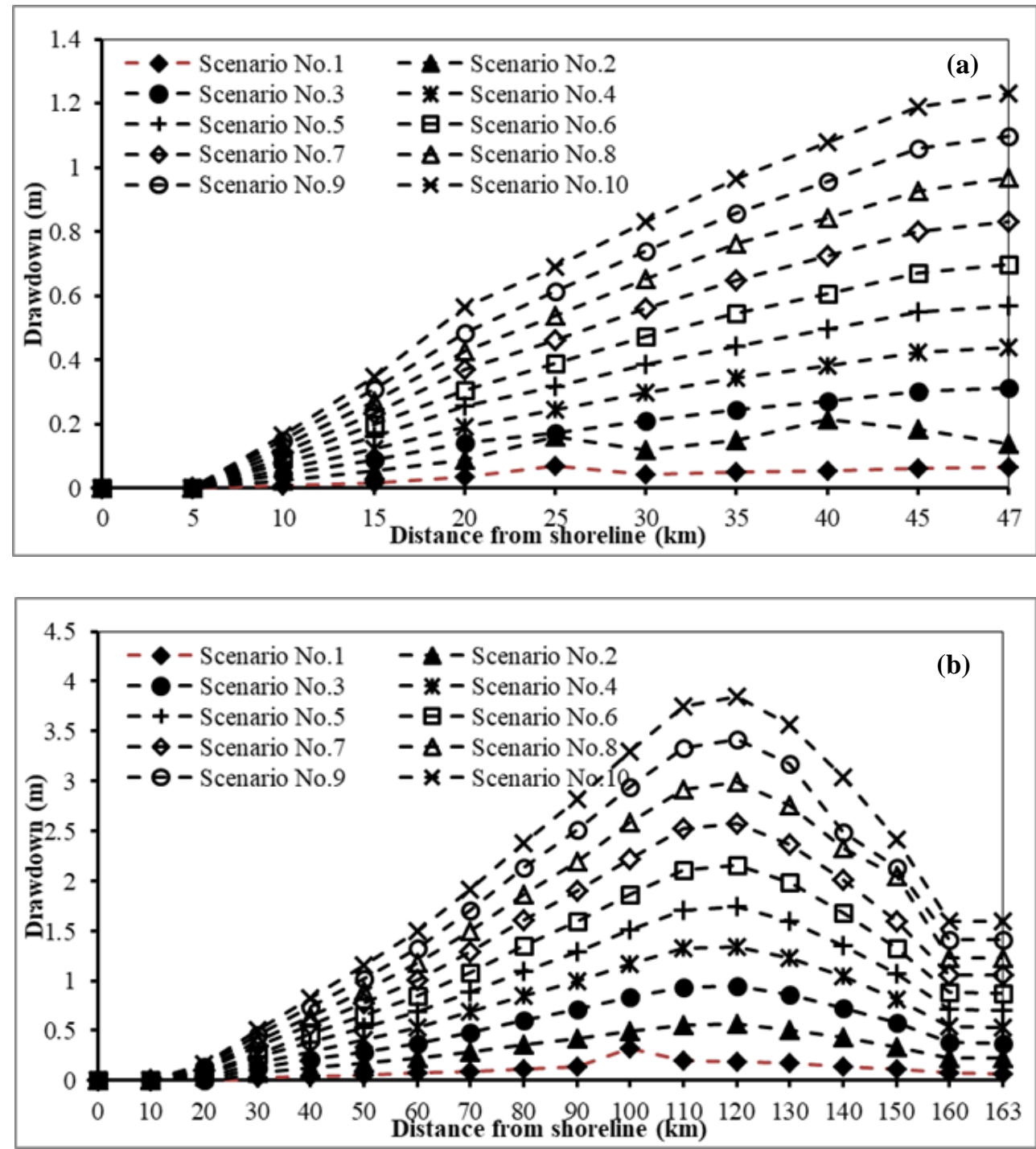


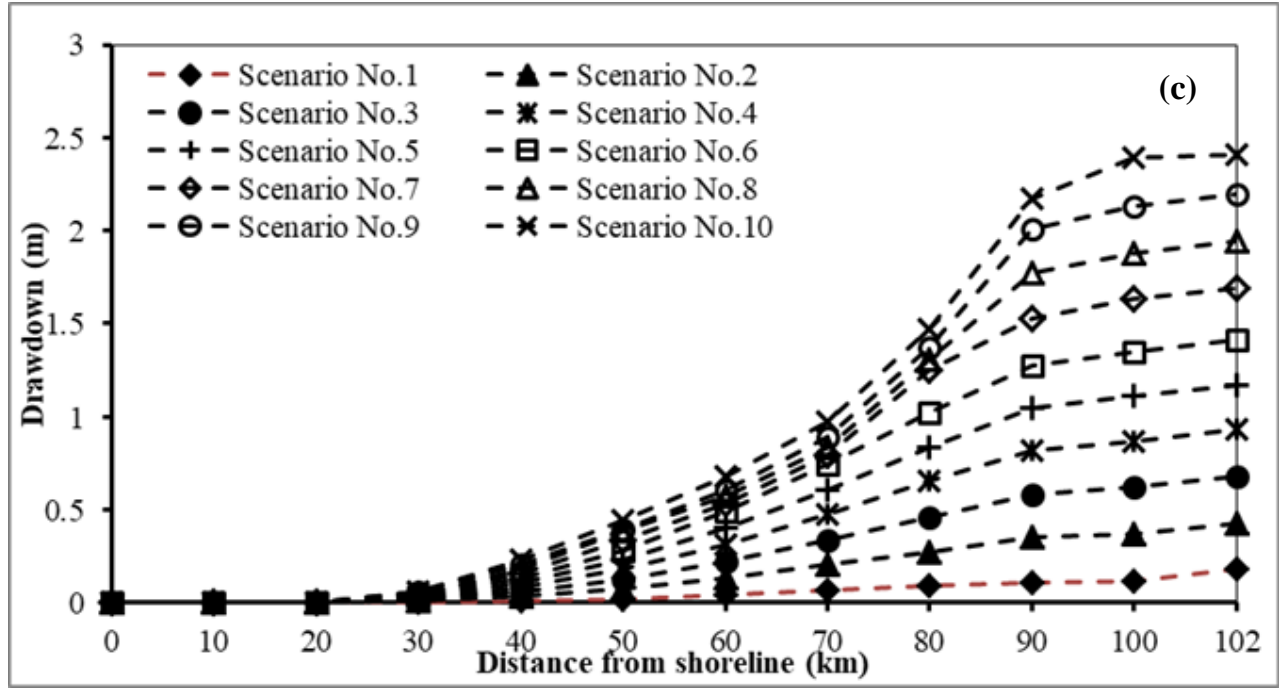

Figure 8. Drawdown in GW level in the NDA for different pumping scenarios for three vertical cross sections: a. 1-1 (western), and b: 2-2 (central), and c.3-3 (Eastern).

\section{Conclusions}

The current study introduces simulating the impact of increasing the abstraction rate on the GW level in the NDA. MODFLOW software has been used to build their dimensional model of the NDA. Aquifer parameters have been adjusted according to literature review and data from RIGW. The simulated GW level has been compared with observed GW level for model calibration and validation. Ten scenarios of increasing the pumping discharges from GW wells have been checked. The results confirmed that increasing the abstraction rates cause decrease in GW level in the NDA. The drawdown of GW level increased with increasing the abstraction rates. In addition, the last scenario by doubled the abstraction rate, is considered the worst scenario compared with the other scenarios. The drawdown in GW level reached 1.32, 1.59, and $2.41 \mathrm{~m}$ in the southern boundaries. The results of this study can be implemented by decision makers for management of GW resources in the NDA.

Conflicts of Interest: The authors declare no conflict of interest.

\section{References}

[1] A. M. Armanuos, A. Allam, and A. M. Negm, “ASSESMENT OF GROUNDWATER VULNERABILITY TO POLLUTION IN WASTERN NILE DELTA AQUIFER, EGYPT,” in Twenty-Second International Water Technology Conference, 2019.

[2] J. Sakiyan and H. Yazicigil, "Sustainable development and management of an aquifer system in western Turkey," Hydrogeol. J., vol. 12, no. 1, pp. 66-80, 2004.

[3] A.-A. I. Kashef, "Salt-Water Intrusion in the Nile Delta," Ground Water, vol. 21, no. 2, pp. 160-167, 1983.

[4] R. A. Wahaab and M. I. Badawy, "Water quality assessment of the River Nile system: an overview," Biomed. Environ. Sci., vol. 17, no. 1, pp. 87-100, 2004.

[5] I. M. El Ramly, "Hydrogeological and water quality characteristics of the saturated zone beneath the various land uses in the Nile Delta region, Egypt," Freshw. Contam., no. 243, pp. 255-261, 1997.

[6] M. Shamrukh, M. Y. Corapcioglu, and F. A. A. Hassona, "Modeling the Effect of Chemical Fertilizers on Ground Water Quality in the Nile Valley Aquifer, Egypt," Groundwater, vol. 39, no. 1, pp. 59-67, 2001.

[7] M. M. A. Shahin, Hydrology of the Nile basin. Elsevier, 1985.

[8] A. M. Armanuos, A. Negm, C. Yoshimura, and O. C. S. Valeriano, "Application of WetSpass model to estimate groundwater recharge variability in the Nile Delta aquifer," Arab. J. Geosci., vol. 9, no. 10, 2016.

[9] A. M. Armanuos et al., "Evaluation of the potential impact of Grand Ethiopian Renaissance Dam and pumping scenarios on groundwater level in the Nile Delta aquifer," Water Supply, vol. 17, no. 5, pp. 1356-1367, 2017.

[10] K. A. Dahab, "Hydrological evaluation of the Nile Delta after the high dam construction." PhD thesis. Faculty of Science. Monofia University. Egypt, 1993.

[11] RIGW, "Hydrogeological map for the Nile Delta area, Scale 1: 500000," 1992.

[12] W. S. Morsy, "Environmental management to groundwater resources for Nile Delta region," PhD, Cairo Univ. Egypt, 2009.

[13] H. M. Serag El Din, "Geological, hydrochemical and hydrological studies on the Nile Delta Quaternary aquifer." 
Ph. D. Thesis, Fac. of Sci., Mansoura Univ, 1989.

[14] M. B. Mabrouk, A. Jonoski, D. Solomatine, and S. Uhlenbrook, "A review of seawater intrusion in the Nile Delta groundwater system - the basis for assessing impacts due to climate changes and water resources development." Copernicus GmbH, 2013.

[15] N. El Arabi, "Environmental Management of Groundwater in Egypt via Artificial Recharge Extending the Practice to Soil Aquifer Treatment (SAT)," Int. J. Environ. Sustain., vol. 1, no. 3, 2012.

[16] J. L. Wilson, L. R. Townley, and A. S. Da Costa, Mathematical development and verification of a finite element aquifer flow model AQUIFEM-1. Massachusetts Institute of Technology, Ralph M. Parsons Laboratory for Water ..., 1979

[17] M. A. Dawoud, M. M. Darwish, and M. M. El-Kady, "GIS-based groundwater management model for Western Nile Delta," Water Resour. Manag., vol. 19, no. 5, pp. 585-604, 2005.

[18] M. S. Abdel-Dayem, "Development of land drainage in Egypt," in Proceedings, Symposium 25th International Course on Land Drainage. ILRI publ, 1987, vol. 42.

[19] A. Shata and I. El Fayoumy, "Remarks on the hydrogeology of the Nile delta, UAR," Hydrol. Deltas, pp. 385-396, 1970.

[20] D. E. Al-Agha, A. Closas, and F. Molle, "Survey of groundwater use in the central part of the Nile Delta," Water salt Manag. Nile Delta Rep., no. 6, 2015.

[21] M. P. Anderson, W. W. Woessner, and R. J. Hunt, "Applied groundwater modeling: Simulation of flow and advective transport," Acad. Press Inc., San Diego, CA. J. Hydrol., vol. 140, pp. 393-395, 1992.

[22] I. M. Abdelaty, H. F. Abd-Elhamid, M. R. Fahmy, and G. M. Abdelaal, "INVESTIGATION OF SOME POTENTIAL PARAMETERS AND ITS IMPACTS ON SALTWATER INTRUSION IN NILE DELTA AQUIFER,” JES. J. Eng. Sci., vol. 42, no. 4, pp. 931-955, 2014. 